\title{
Construction of Green Theoretical Framework of Coal Resource Capitalization
}

\author{
Xueyi Zhu' ${ }^{1}$ Liangfeng Zhu ${ }^{2 *}$ \\ ${ }^{1}$ Business School, Nantong Institute of Technology, Nantong, china \\ ${ }^{2}$ Business School, Changzhou University, Changzhou, China \\ Email:xyzhu@cumt.edu.cn, *717659882@qq.com
}

How to cite this paper: Zhu, X.Y. and Zhu, L.F. (2020) Construction of Green Theoretical Framework of Coal Resource Capitalization. International Journal of Clean Coal and Energy, 9, 15-25.

https://doi.org/10.4236/ijcce.2020.92002

Received: February 15, 2020

Accepted: March 28, 2020

Published: March 31, 2020

Copyright $\odot 2020$ by author(s) and Scientific Research Publishing Inc. This work is licensed under the Creative Commons Attribution International License (CC BY 4.0).

http://creativecommons.org/licenses/by/4.0/

\begin{abstract}
In recent years, the Chinese government has asked enterprises to follow the path of "green development". This requirement naturally becomes the guiding ideology of coal resource capitalization theory. this paper focuses on the core contents of the green development of coal resource capitalization, and uses the software of ROSTCM6 and UCINET to construct six frameworks of the green theory of coal resource capitalization with the method of "Condensed Subgroup": the basic theory of capitalization, the conservation theory of capitalization, the environmental protection theory of capitalization, the harmonious coexistence theory of capitalization, the mainline development theory of ecological industry of capitalization Industrial theory, benign cycle sustainable development theory of capitalization, the paper further designs the outline content of the framework.
\end{abstract}

\section{Keywords}

Condensed Subgroup Method, Coal Resources, Capitalization, Ecological Civilization, Green Theory

\section{Introduction}

The "ecological" theory of coal resource capitalization is a theory of coal resource capitalization revealed from the angle of "ecological civilization" [1] [2]. China's research on "capitalization of coal resources" began in 2000, and its essence is "paid mining" [3]. In fact, China's coal resources were allocated by the state to enterprises for free mining before 1999, but from 2000 to 2007, China's stock of coal resources and incremental coal resources in the country's mineral resources first fully realized paid mining [4], that is, enterprises need to buy mining rights before mining.

*Corresponding author. 
This kind of paid mining promotes the vigorous development of coal economy. The development data from 2001 to 2011 show that China's coal economy has entered a "golden" development period [5]. However, with the end of the "golden" period of coal economy, three major problems are highlighted: one is the overcapacity of coal [6]; the other is the destruction of the ecological environment; and the third is the pollution of the environment caused by extensive consumption of coal. The emergence of these problems has aroused the attention of the state to the whole problem of natural resources management. The state has constantly formulated policies and issued documents requiring that the management of natural resources be raised to the height of the construction of "ecological civilization". Natural resources management departments should compile the balance sheet of natural resources [7] and explore new ways of high-quality development oriented by ecological priority and green development. Guided by the concept of "green development", China's coal industry integrates the construction idea of "ecological civilization" into the theoretical system of coal resource capitalization. It is the need of "promoting advantages and eliminating disadvantages" in the process of coal economic development, the need for healthy, sustainable and high-quality development of coal economy, and the benefit of green development of coal economy for the needs of the people.

\section{Construction Method and Thought of Green Theory of Capitalization of Coal Resources}

\subsection{Theory Construction Method}

There are three ways to construct the theory of coal resource capitalization:

The first is to use the effective method of constructing accounting theory for reference [8]. This is the most basic and important method. Because the concept of "capitalization" defined in China's "Economic Dictionary" originated from accounting concept, which means that accounting classifies some expenditure as "capital expenditure" and carries out "capitalization" management method [9]. The capitalization of coal resources is based on the connotation of accounting capitalization.

The second is to draw lessons from the previous research results in the theoretical construction of effective methods. There are four commonly used methods: pragmatism, authoritarianism, deduction and induction. Since the introduction of coal resource capitalization in 2000 (after the appearance of the first article), only one article on "accounting treatment of coal resource capitalization" has appeared in China Journal Network (searching for "coal resource capitalization" under the title of CNKI) [10]. This article is only one of the accounting transaction process methods (pragmatism method), which can only play a certain role in improving the content of accounting theory, and cannot become an important method to construct theory. Then from the "National Library of China.National Digital Library of China" to search for the "book" of "capitalization of coal resources", only Zhu Liangfeng's "Study on Supporting Theory and Op- 
erating Efficiency about Capitalization of Coal Resources" in 2017 is a monograph [11]. This monograph uses deductive method to describe the basic framework of the ecological theory of coal resource capitalization, which can provide useful reference for this paper.

Thirdly, combining with the characteristics of the times, we should use innovative theoretical construction methods. This innovative method is mainly "condensed subgroup method". It is a sociological method of word segmentation, clustering and focusing on documents, articles, speeches, events and acts (including specialized channels and network channels) that are widely collected by software. Since the theory of coal resource capitalization in China is still in its infancy. This systematic theoretical system has not yet been formed, various scattered viewpoints need to be sorted out and upgraded, and to integrate into the advanced theories, ideas and ideas of the new era, the "condensed subgroup method" can better reflect the new requirements of building an innovative theoretical system.

\subsection{Thoughts on the Construction of Green Theory of Capitalization of Coal Resources}

To construct the theoretical system of "ecology" of coal resource capitalization, we should take two steps: first, build a framework, and then refine it. Based on the green theory of coal resource capitalization, this paper puts forward the basic framework of the green theory of coal resource capitalization. The basic requirements of this framework are: the connotation of theoretical concepts, construction requirements, characteristics of the times and innovation of construction methods.

According to the above basic requirements, the idea of constructing the theoretical framework of "green" of coal resources capitalization (logical path) is: 1) guided by the general goal and requirements of the construction of "ecological civilization" in today's society, guided by the existing problems in the development and utilization of coal resources; 2) guided by the development of coal economy in the past, especially based on the practice and research results of the development and utilization of coal resources, a theoretical framework is formed by focusing on the research content with the method of "condensed subgroup". 3) The framework structure of the green theory of coal resources capitalization is constructed. Among them, referring to the construction method of accounting theory, the basic theory is put forward to the front of the branch theory, so that the branch theory is delineated within the scope of the research subject and built on the platform of the basic theory.

\section{Constructing the Green Theoretical Framework of Capitalization of Coal Resources by Condensation Subgroup Method}

The condensed subgroup method is an innovative method to construct a theoretical framework in today's society. The theory created by this method not only 
originates from practice, but also can guide practice well. It not only promotes accounting practice to the height of accounting theory, but also raises social practice to the theoretical height of economic management and social management. the agglomerative subgroup method is not the author's creation. The author's innovation is to apply this method to the construction of resource management innovation theory, which is different from other theoretical construction methods.

\subsection{Guided by the National Policy of "Ecological Civilization"}

Since October 2007, the 17th and 18th congresses of the Communist Party of China have put forward the goal of "building an eco-civilization" country. They have made "building an eco-civilization" an important part of the overall layout of the cause of socialism with Chinese characteristics and "integrating it into all aspects of economic construction, political construction, cultural construction and social construction" and the whole process. In order to implement this goal, in August 2016, Fujian Province was listed as a "national ecological civilization pilot area" to build [12]. On August 23, 2016, Chinese President Xi Jinping asked Qinghai Province to do a good job of development and utilization under the premise of protecting the ecological environment [13]. On March 5, 2019, Xi Jinping also asked Inner Mongolia to "explore a new way of high-quality development oriented by ecological priority and green development". The introduction of these policies by the state and the requirements put forward by the state leaders should be the guiding ideology of the "green" theory of coal resource capitalization.

\subsection{Connecting with "Visual Structural Diagram" of Network Density}

1) Word segmentation and word frequency analysis using "ROSTCM6" software

ROST Content Mining System User Manual Version 6.0 was developed by the ROST Virtual Learning Team of Wuhan University in September 2010.

The important functions of the system are: segmentation, character frequency statistics, word frequency statistics, clustering, classification, emotional analysis (including simple and complex), co-occurrence analysis, and co-occurrence analysis for papers, microblogs, blogs, forums, webpages, books, chat records, e-mail, local text format files, various text fields in the database. Citation analysis, dependency analysis, semantic network, social network, co-occurrence matrix can also be analyzed. Using these functions to construct the theoretical framework of coal resource capitalization is as follows:

a) Collect five thematic articles. Through China HowNet (CNKI) and Chinese Social Sciences Citation Database (CSSCI), we collected articles about "resource conservation", "environment friendliness", "harmonious coexistence", "sustainable prosperity", "ecological industry", especially "overview", and downloaded the text in the format of *.txt. Using "ROSTCM6" software for word segmenta- 
tion, word frequency table is generated. See Table 1.

b) Collect articles on "capitalization of coal resources". Collect "coal resource capitalization" articles through China HowNet, and download the text in *.TXT format. Using "ROSTCM6" software for word segmentation, a word frequency table is generated. See Table 2.

c) Word frequency matrix is compiled. Based on the word frequency of "coal resource capitalization" and the word frequency of five research hotspots, a word frequency matrix (same word frequency summary, elimination of useless word frequency such as "research institute") is compiled. See Table 3.

Table 1. Frequency table of five research hotspots on ecological civilization (Unit: 10,000).

\begin{tabular}{|c|c|c|c|c|c|c|c|c|c|}
\hline \multicolumn{2}{|l|}{$\begin{array}{l}\text { Resource conservation } \\
\text { word frequency }\end{array}$} & \multicolumn{2}{|c|}{$\begin{array}{l}\text { Environment friendliness } \\
\text { word frequency }\end{array}$} & \multicolumn{2}{|c|}{$\begin{array}{l}\text { Harmonious coexistence } \\
\text { word frequency }\end{array}$} & \multicolumn{2}{|c|}{$\begin{array}{l}\text { Sustainable prosperity } \\
\text { word frequency }\end{array}$} & \multicolumn{2}{|l|}{$\begin{array}{l}\text { Ecological industry } \\
\text { word frequency }\end{array}$} \\
\hline Technology & 37 & Environmental Science & 270 & Development & 282 & Economics & 128 & Ecology & 509 \\
\hline Research & 34 & Development & 145 & Innovate & 69 & China & 89 & Development & 220 \\
\hline Economics & 26 & Sociology & 138 & Ecology & 53 & Increase & 66 & Clean & 135 \\
\hline Problem & 24 & China & 122 & Economics & 47 & Green & 56 & Environmental Science & 128 \\
\hline Seminar & 19 & Friendly & 97 & Green & 45 & Development & 47 & Economics & 109 \\
\hline Innovate & 19 & Economics & 90 & China & 41 & Wages & 45 & Research & 98 \\
\hline China & 18 & Build & 74 & Idea & 40 & Design & 43 & Industry & 95 \\
\hline Sustainable Development & 18 & Resources & 73 & To Open up & 39 & Labour & 38 & System & 89 \\
\hline Country & 16 & Technology & 69 & Sociology & 38 & Investment & 32 & Agriculture & 80 \\
\hline Development & 14 & Ecology & 57 & The People & 34 & Increase & 32 & China & 73 \\
\hline Proposal & 11 & Enterprise & 57 & China & 34 & China & 32 & Resources & 73 \\
\hline Sociology & 11 & Government & 55 & Comprehensive & 31 & Rise & 30 & Enterprise & 64 \\
\hline Environmental Science & 10 & Climate & 49 & Insist & 31 & Expert & 29 & Theory & 63 \\
\hline Build & 10 & Change & 46 & Realization & 30 & Economics & 29 & Quality & 61 \\
\hline- & - & - & - & - & - & - & - & - & - \\
\hline
\end{tabular}

Table 2. Frequency table of capitalization of coal resources (Unit: 10,000).

\begin{tabular}{cccccccc}
\hline \multicolumn{7}{c}{ Capitalization of Coal Resources word frequency } & \\
Coal & 337 & Method & 42 & Accounting & 25 & Mining Rights & 23 \\
Resources & 327 & Country & 42 & Realization & 25 & Process & 22 \\
Enterprise & 125 & Administration & 41 & Subject & 25 & Increase & 22 \\
Capital & 117 & Prospecting & 38 & Handle & 25 & Cost & 20 \\
Marketing & 88 & Coal mine & 35 & Ownership & 24 & Management & 19 \\
Value & 86 & Owner & 34 & Interest & 24 & Economics & 19 \\
China & 48 & Assets & 33 & Service & 24 & Development & 19 \\
Exploitation & 45 & Strategy & 31 & Development & 23 & Security & 19 \\
Market & 45 & Profit & 28 & Equity & 23 & Utilize & 19 \\
Property Right & 43 & Large & 26 & Property & 23 & Ability & 18
\end{tabular}


Table 3. Matrix frequency table of capitalization of coal resources and ecological civilization (Unit: 10,000).

\begin{tabular}{ccccccc}
\hline & Capitalization & $\begin{array}{c}\text { Resource } \\
\text { conservation }\end{array}$ & $\begin{array}{c}\text { Environment } \\
\text { friendliness }\end{array}$ & $\begin{array}{c}\text { Harmonious } \\
\text { coexistence }\end{array}$ & prosperity & $\begin{array}{c}\text { Ecological } \\
\text { industry }\end{array}$ \\
\hline Coal & 337 & 135 & 82 & 80 & 96 & 168 \\
Resources & 332 & 14 & 73 & 68 & 8 & 73 \\
Enterprise & 125 & 6 & 62 & 6 & 16 & 70 \\
Capital & 117 & 0 & 0 & 0 & 10 & 0 \\
Value & 86 & 0 & 6 & 0 & 0 & 6 \\
Country & 169 & 42 & 182 & 152 & 183 & 180 \\
Market & 45 & 0 & 6 & 12 & 15 & 14 \\
Administration & 41 & 6 & 26 & 3 & 7 & 31 \\
Strategy & 31 & 8 & 21 & 10 & 16 & 22 \\
Realization & 25 & 0 & 30 & 30 & 19 & 28 \\
- & - & - & - & - & - & - \\
\hline
\end{tabular}

\section{2) Using UCINET software to analyze network density to form a visual} structure chart

UCINET (University of California at Irvine NETwork) is a powerful social network analysis software. It was originally written by Linton Freeman, an authoritative scholar of social network research at the University of California, Irvine, and later expanded by Stephen Bogart, Stephen Borgatti, Martin Everett and Linton Freeman. The software includes NetDraw for one-dimensional and two-dimensional data analysis, Mage for three-dimensional display and analysis, etc. It also integrates Pajek's Free application program for large-scale network analysis. Using UCINET software, we can read text files, KrackPlot, Pajek, Negopy, VNA and other formats, and do centrality analysis, subgroup analysis, role analysis and permutation-based statistical analysis, especially with strong matrix analysis function.

Input Table 3 into UCINET software to form "*.\#\#h" File-Form "* GTO.\#\#h" file by "transformation" and "bisection"- through the operation of "network", "cohesion" and "density", the average value of density matrix is 0.6347 (standard deviation is 0.4815 )-through the operation of "visualization", "network" and "opening", the following "visualization structure chart of green theory of coal resource capitalization" is formed. See Figure 1.

From the small box in Figure 1, it can be seen that the "capitalization" box is on the right, while the "resource conservation", "environment friendliness", "ecological industry", "harmonious coexistence" and "sustainable prosperity" box are on the left from top to bottom. The six boxes are in the center, with the matrix average density of 0.6347 . 


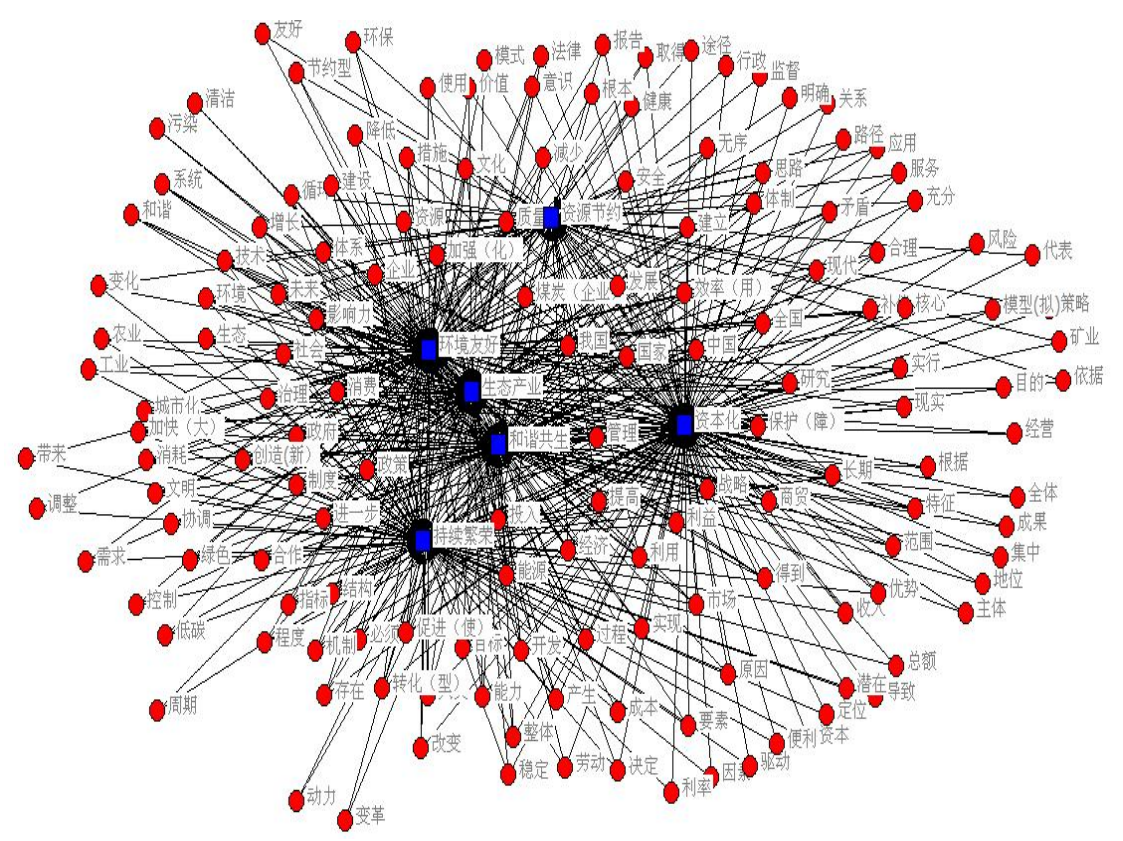

Figure 1. Visualization structure chart of green theory of coal resource capitalization.

3) The Framework of Green theory Based on the "agglomerated subgroup graph" of network centricity

A cohesive subgroup is a subset of actors. In this subset, there are direct, close, relatively strong, frequent or positive relationships among actors, which can reveal and characterize the sub-structure state within the group, including the number of cohesive subgroups in the network, which city members each cohesive subgroup contains, the relationship between cohesive subgroups, their connection modes and dimensions of cohesive subgroups, etc.

Using UCINET software, through the operation of "network", "role \& location", "structure" and "CONCOR", the "cohesive subgroup diagram of green theory framework of coal resource capitalization" is generated. See Figure 2.

\section{Revealing the Theoretical Framework of "Green" for Capitalization of Coal Resources}

It can be seen from Figure 2 that the green theory of coal resource capitalization consists of six parts: 1) basic theory of capitalization; 2) resource conservation theory, which is refined into conservation theory of capitalization; 3) environmental friendliness theory, which is refined into environmental protection theory of capitalization; 4) harmonious coexistence theory, which is determined as harmonious coexistence theory of capitalization; 5) ecological industry theory, which is refined into main line development theory of ecological industry of capitalization; 6) the theory of sustainable prosperity, refined into benign cycle sustainable development theory of capitalization. 2)-6) belong to the branch theory of capitalization. The resulting green theoretical framework of coal resource capitalization is shown in Figure 3. 


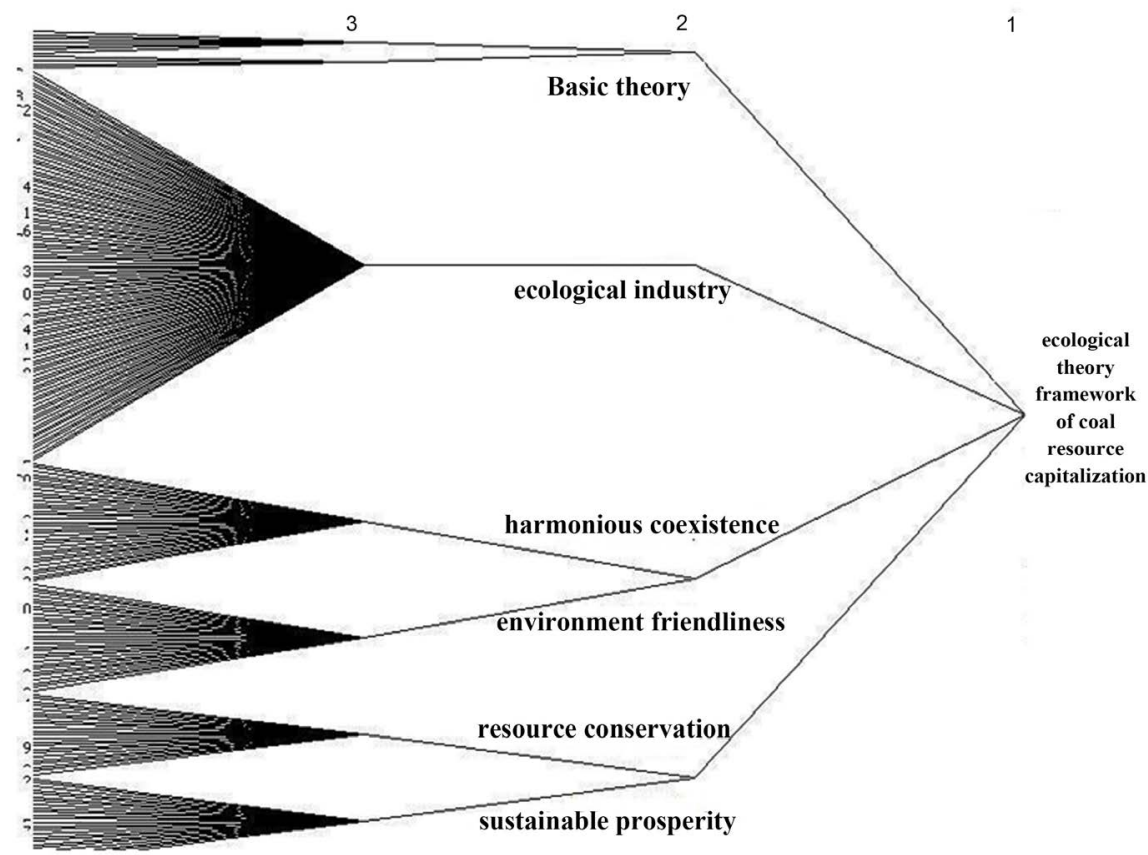

Figure 2. Cohesive subgroup diagram of green theory framework of coal resource capitalization.

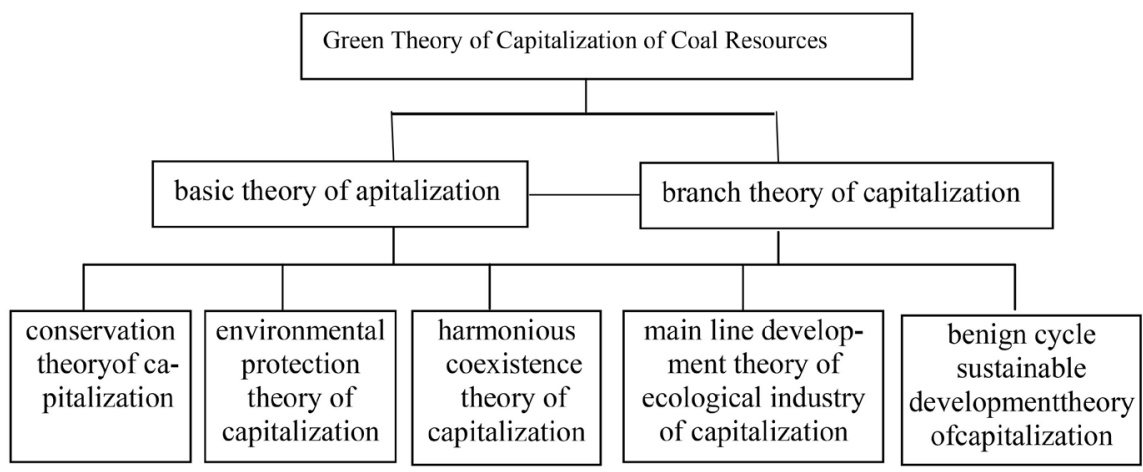

Figure 3. The theoretical framework of green for capitalization of coal resources.

\section{Green Theoretical Framework of Coal Resource Capitalization Setting of Outline Content}

First, the outline content design of the basic theory of coal resource capitalization. Including: the concept of capitalization and coal resource capitalization; the concept of ecological civilization and its "green" development; the theory of ecological civilization "layout" of coal resource capitalization.

Second, the outline content design of the conservation theory of coal resource capitalization. Including: improve the "recovery rate" of coal resources; reduce the consumption rate of coal resources; improve the consumption rate of self-produced coal; improve the supply rate of high-quality coal resources.

Third, the outline content design of the environmental protection theory of coal resource capitalization. Including: reducing the emission of pollutants in the process of coal mining and washing; making full use of coal gangue, the acces- 
sory product of coal production; strictly supervising the coal enterprises to mine while treating; effectively disposing the "waste" of abandoned mines; carrying out the deep processing business of coal to produce more clean and efficient energy.

Fourth, the outline content design of the harmonious coexistence theory of coal resources capitalization. Including: taking coal resources as the "base" should be based on human living conditions; when obtaining the capital income of coal resources, the rights and interests of the whole mining area should be maintained [14]; and the compensation mechanism of mining area environmental governance should be established.

Fifth, the outline content design of the main line development theory of ecological industry of coal resources capitalization. Including: the determination of the ultimate goal of coal ecological industrialization: to maximize the use of resources, minimize environmental pollution, minimize ecological damage and improve the efficiency of capital operation in the process of production and development of coal industry [15]; new coal mines should take "Coal Ecological Park" as the standard; new coal bases should take "clean" energy as the leading role; coal mining areas should take coal industry as the leading role, with Other ecological industries will be developed in an all-round way; when the mine is abandoned, it is necessary to carry out ecological restoration, so as to provide normal production, life and entertainment ecological places for people in the mining area.

Sixth, the outline content design of the benign cycle sustainable development theory of coal resources capitalization. Including: the key to determine the development of coal economic cycle is to extend the coal industry chain; to extend the coal industry chain, we need to achieve the unity of economic benefits, social benefits and environmental benefits; the speed of efficient extension of the coal industry chain depends on the level of scientific and technological development, the level of cost-effectiveness and the degree of market acceptance; the theory of coal resource capitalization cycle development should have the universality of industry management and the world trend, the advanced nature of source management [16].

\section{Research Conclusion}

The conclusion is that simultaneous interpreting the theory framework of coal resources capitalization by using the condensed subgroup method is an innovation. Compared with the traditional theory construction method, the basic data is more extensive, the arrangement is more clear, the generalization is more comprehensive and the practicability is stronger. Six green theoretical frameworks of coal resource capitalization have been formed by focusing on this method: the basic theory of capitalization is the basis of the green theoretical framework; the conservation theory of capitalization is the starting point of the branch theory of capitalization; the environmental protection theory of capitalization and the theory of harmonious coexistence are the core of the branch theory of capitaliza- 
tion; the mainline development theory of ecological industry of capitalization is the focus of the branch theory of capitalization; benign cycle sustainable development theory of capitalization is the foothold of the branch theory of capitalization [17]. These six framework theories constitute a new theoretical system of coal resource capitalization, which has a strong guiding significance for the prosperity and development of coal economy.

\section{Acknowledgements}

This research is funded by Research Project on First-Class Key Disciplines of Industry \& Business Administration under the 13th Five-Year Plan of Jiangsu Province (SJY201609), Research Base of Harmonious Development of Industry in Tonghu, an off (SJSZ201716) and Professor and Doctor's Foundation of Nantong Institute of Technology (NIT) (201823).

\section{Conflicts of Interest}

The authors declare no conflicts of interest regarding the publication of this paper.

\section{References}

[1] Shen, Z.-Y. and Zhu, X.-Y. (2000)Capitalization: A Strategy for Sustainable Utilization of Coal Resources. Journal of China Coal Economic College, 1, 66-69. https://kns.cnki.net/KCMS/detail/detail.aspx?dbcode=CJFD\&dbname=CJFD2000\&fil ename=BXYX200001018\&v=MDY4Njg3RGgxVDNxVHJXTTFGckNVUjdxZlpPZG5 GeWpsVzc3TUp6WFNkckc0SHRITXJvOUViSVI4ZVgxTHV4WVM

[2] Shen, Z.-Y. and Zhu, X.-Y. (2000) Capitalization: A Strategy for Sustainable Utilization of Coal Resources. Industrial Economy, 6, 46-49.

http://ipub.exuezhe.com/paper.html?id=136021\&kw=\%E6\%9C\%B1\%E5\%AD\%A6 \%E4\%B9\%89

[3] Zhu, X.-Y. and Zhang, Y.-J. (2008) Capitalization Reform of Mineral Resources in China. Resources Science, 1, 134-139.

https://kns.cnki.net/KCMS/detail/detail.aspx?dbcode=CJFQ\&dbname=CJFD2008\&fil ename=ZRZY200801020\&uid=WEEvREcwSlJHSldRa1FhcTdnTnhXY20wTWFjKzB2 Y2x1OGNMcVJlMzVXMD0=\$9A4hF_YAuvQ5obgVAqNKPCYcEjKensW4IQMovw HtwkF4VYPoHbKxJw!!\&v=MjgzOTFNcm85SFpJUjhlWDFMdXhZUzdEaDFUM3F UcldNMUZyQ1VSN3FmWk9kbkZ5cmxVcnpQUHovUmQ3RzRIdG4

[4] Zhu, X.-Y. (2008) Research on Theory and Application of Mineral Resources Equity. Social Science Academic Press (China), Beijing, 1-335.

http://find.nlc.cn/search/showDocDetails?docId=1715788303891498255\&dataSourc e=ucs01fzdzsysj\&query=\%E7\%9F\%BF\%E4\%BA\%A7\%E8\%B5\%84\%E6\%BA\%90\%E 6\%9D\%83\%E7\%9B\%8A\%E7\%90\%86\%E8\%AE\%BA\%E4\%B8\%8E\%E5\%BA\%94\%E7 \%94\%A8\%E7\%A0\%94\%E7\%A9\%B6

[5] Su, L.-G. (2011) Thoughts on Changing the Development Mode of Coal Economy. Coal Economic Research, 1, 9-12. https://www.cnki.net/kcms/doi/10.13202/j.cnki.cer.2011.01.009.html

[6] Sohu. China's Coal Overcapacity in 2015 Was 1.748 Billion Tons. http://www.sohu.com/a/54417362_246933 
[7] China National Committee for Terms in Sciences and Technologies. Natural capital. http://baike.baidu.com/view/3849662.htm

[8] Riahi-Belkaoui, A. (2004) Accounting Theory. 4th Edition, Shanghai University of Finance \& Economics Press, Shanghai. http://book.kongfz.com/7065/1363839732/

[9] Xia, Z.N., et al. (2003) Dacihai Philosophy Volume. Shanghai Dictionary Publishing House, Shanghai, 107-108.

http://find.nlc.cn/search/showDocDetails?docId=2308752036857409561\&dataSourc e=ucs01\&query=\%E5\%A4\%A7\%E8\%BE\%9E\%E6\%B5\%B7\%C2\%B7\%E5\%93\%B2\% E5\%AD\%A6\%E5\%8D\%B7

[10] Wang, Z.W. (2012) Thoughts on Accounting Processing of Capitalization of Coal Resources. Modern Business, 11, 251-252.

https://www.cnki.net/kcms/doi/10.14097/j.cnki.5392/2012.11.009.html

[11] Zhu, L.F. (2017) Stuty on Support Theory and Operation Efficiency about Capitalization of Coal Resources. China Economic Publishing House, Beijing.

http://find.nlc.cn/search/showDocDetails?docId=-7076464536549756481\&dataSour ce=ucs01\&query=\%E7\%85\%A4\%E7\%82\%AD\%E8\%B5\%84\%E6\%BA \%90\%E8\%B5 \%84\%E6\%9C\%AC\%E5\%8C\%96\%E6\%94\%AF\%E6\%92\%91\%E7\%90\%86\%E8\%AE $\%$ BA\%E5\%8F\%8A\%E8\%BF\%90\%E4\%BD\%9C\%E6\%95\%88\%E7\%8E\%87\%E7\%A0\%9 $\underline{4 \% \mathrm{E} 7 \% \mathrm{~A} 9 \mathrm{~B} 6}$

[12] China Civilization Network Fujian Has Become the First Experimental Area of Ecological Civilization in China. http://www.wenming.cn/syjj/dfcz/fj/201608/t20160824_3615618.shtml

[13] Sina Public Welfare Network (2016) Xi Jinping's Qinghai Inspection: Developing and Utilizing Well on the Premise of Protecting Ecology. Beijing Times. http://gongyi.sina.com.cn/gyzx/hg/2016-08-23/doc-ifxvcsrm2257977.shtml

[14] Zhu, L.F. and Zhu, X.Y. (2017) Analysis of the Relationship about China's Environmental Governance and Economic Benefit of Coal Industrial Enterprise. Journal of Management Policies and Practices, 5, 31-39.

http://jmppnet.com/vol-5-no-2-december-2017-abstract-5-jmpp https://doi.org/10.15640/jmpp.v5n1a5

[15] Zhu, L.F. and Zhu, X.Y. (2019) Energy Policy, Market Environment and the Economic Benefits of Enterprises: Evidence from China's Petrochemical Enterprises. Natural Hazards, 95, 113-127.

https://link.springer.com/article/10.1007/s11069-019-03579-3 https://doi.org/10.1007/s11069-019-03579-3

[16] Zhu, L.F. and Zhu, X.Y. (2017) Study on the "Bottoming Out" Recovery of Coal Capacity in China. International Journal of Economic Perspectives, 11, 1355-1361.

https://www.scopus.com/record/display.uri?eid=2-s2.0-85055499413\&origin=resultsli st\&sort=plf-f\&src=s\&sid=e13700aa22817706edcdd18d4dab4375\&sot=autdocs\&sdt=a utdocs\&sl=18\&s=AU-ID\%2843261957300\%29\&relpos=0\&citeCnt=0\&searchTerm $=$

[17] Zhu, X.Y. and Zhu, L.F. (2017) The Practice of Value Increment Target of Management Accounting-As Exemplified by the Private Enterprises within Huaihai Holdings Group. Management Review, 29, 262-272.

https://www.cnki.net/kcms/doi/10.14120/j.cnki.cn11-5057/f.2017.09.023.html 